\title{
INTERLUDE: A TOPOGRAPHY OF CORRUPTION IN TANZANIA
}

\begin{abstract}
Despite the three common enemies of Tanzania's development namely ignorance diseases and poverty [sic], corruption has emerged the fourth. Suggest the root causes of corruption and the ways to stop this social problem in not less than 250 words. ${ }^{1}$
\end{abstract}

Tanzanians have got so used to corruption that many have accepted it as part of the social scene in the country. What has changed since 2007 is that for the first time corruption has been brought out into the open. It has become not only a subject of political gossip but part of the official discourse. Corruption has shifted from being something people take for granted to being the subject of a scandal. ${ }^{2}$

Against the backdrop of the development discourse on corruption and governance, the first part of this study (Chapter 1 and 2) outlined two further discourses on corruption. The academic discourse, in conjunction with the development discourse on corruption, are discourses which have successfully hegemonised the meaning of corruption. They have constructed generally acknowledged ways of understanding, seeing, and practicing development and political order in African states around the term. The discourse on emancipatory politics sketched out in the previous chapter is more disparate, less coherent. It links an analytical strategy, ${ }^{3}$ i.e. post-Marxist political theory, to a discussion of historically and conceptually formative social spheres, agents and practices of emancipation. In fact, it redefines the concept of discourse, by removing the inherent suspicion of repression, and theorising it as a key mechanism of (a priori open) social and political operations. The analytical strategy developed in the last chapter is tapered in specific reference to African political orders. In this way, the first part of this book lays the groundwork for an empirical investigation into the ways in which corruption is constructed, more precisely: the ways in which specific constructions of corruption frame, shape, open or close spaces of localised social agency, here understood in an emancipatory sense.

1 Exam question of the Certificate of Secondary Education Examination (O-levels) at Kisimiri School, October 2008 (courtesy of Sibylle Ganz-Koechlin).

2 See Hyden/Mmuya 2008: 104.

3 Akerstrom Anderson defines an analytical strategy as "a way to stress the deliberate choice and its implications, and to highlight that this choice could be made differently with different implications in respect of the emerging object" (Akerstrom Anderson 2003: XIII; emphasis in original). 
The second part of this book, for which the groundwork is being laid in this interlude, is dedicated to this empirical exploration, which I approach in three narrative steps. In this interlude I will provide an outline of the discursive body that development, governance and corruption indicators construct on an aggregate level. What I seek to do here is to sketch out a topography, which will form part of the landscape in which the casestudies on corruption, social agents and the construction industry of the following two chapters are situated. In particular, the main statements made in quantitative and qualitative surveys on governance and corruption in Tanzania over the past two decades are summed up. The purpose of this interlude is twofold: firstly, to provide a glimpse into the ways that development, governance and corruption are constructed and linked in 'scientifically', i.e. statistically validated ways, producing rankings between countries regionally and world-wide, and thus emphasising numerical correlations between different features dimensions deemed important to define development (currently: governance and corruption). The second, and for my purposes more important intention is to describe the ways in which corruption is perceived and represented in Tanzania itself, and thus to set the stage for the case studies. In the past decade, the increasing number of publically available reports and citizens' surveys on corruption have served to profile a 'corruption landscape' of its own, by employing conventionally acknowledged methods of measuring reality and thus creating a means of articulating corruption in the public sphere. How powerful these articulations are in terms of inscribing processes of social change is another matter, and one which I shall attempt to explore from a completely different perspective, namely that of professional associations in the construction industry of Dar es Salaam (Chapters 3 and 4).

\section{Why a Topography?}

As was discussed in the Introduction, 'mapping' corruption is a highly popular technique of the 'Anti-Corruption Machine' of foreign aid to render the scale and the type of corruption in countries or sectors visible, and on the basis of this knowledge to design appropriate interventions. ${ }^{4}$ Certainly with regard to the first objective, the 'rendering visible', such a profiling is also the intention of this chapter, namely to provide some

\footnotetext{
${ }^{4}$ For an example and overview see the study undertaken Transparency International 2007 on behalf of the UNDP's Democratic Governance Group.
} 
bearing points in discussing corruption in Tanzania. I have chosen the term 'topography' rather than mapping; not only to distinguish it from the intervention-geared term of 'mapping', but also because the term 'topography' provides perhaps a more appropriate description of the steps undertaken here, which is to situate the case-studies of social agents and corruption in Tanzania. For this purpose, tracing corruption through the lens of indices and reports provides a (not the only, but an important) frame of reference of quantitative as well as qualitative statements made on corruption in Tanzania, of the relations amongst components of corruption in Tanzania, and of some of the representations of corruption by specific actors inside Tanzania. In this way, I seek to describe the 'surface' of corruption in Tanzania as captured, analysed and quantified in a variety of reports and indices. I hope to provide a situation (in the sense of situating) of corruption in Tanzania, informed by different types of knowledge and statements (i.e. quantitative, qualitative, comparative, sectoral, etc.). This topography can be analysed with regard to the inferences to 'development' or to 'governance' in Tanzania. But for my purposes far more important is quite literally to sketch out the landscape in which social actors operate in, to describe the most prominent surveys and reports that are in the public domain, which are available to and inscribed in discourses on corruption. This is a necessary operation before zooming in on to the case-studies that will be explored in the following chapters, not least to render them legible with regard to other discourses of corruption.

In the following sections of this interlude, I shall therefore undertake two steps. Firstly, I will seek to sketch out a broad landscape, demarcating significant bearing points on development and governance in Tanzania. Against the broader background of some developmental indicators and assessments, more recent ways of thinking about development in form of governance and corruption indices are included. These indices mostly have a global or at least regional scope, and thus allow a bird's eye view of this landscape in Tanzania. Their power lies in aggregation, etching few but condensed and memorable statements into the discursive surface of 'corruption'.

The second step seeks to compile perspectives that magnify more localised perspectives of corruption in Tanzania, grappling with the rather 'messier' landscape of such qualitative documents. In this section, I will proceed chronologically rather than substantively, for two reasons. Firstly, methodological representations of corruption in Tanzania are relatively recent, and a chronological account captures the speed and the new types of articulations more clearly. Secondly, a chronological account allows for the two case-studies that will be outlined in Chapters 3 and 4 to be situated accordingly within a temporalised landscape. 
The various facets on corruption in Tanzania highlighted through these various perspectives by no means outline a comprehensive or even precise survey of 'corruption' in Tanzania. But as should be clear by now, this is not the intention. The intention is to describe the surface of corruption, indicating some relevant features, positions and elevations that provide bearing points for other articulations of corruption by social actors in Tanzania.

\section{A Bird's Eye View: Development, Governance and Corruption in Tanzania}

Since independence in 1962, Tanzania has managed to remain one of the most peaceful states of the region; unlike other states, it has survived the varying levels and forms of economic hardship and far-reaching structural reforms without severe political challenges. ${ }^{5}$ In fact, in the nineties Tanzania was considered to be one of Africa's so-called governance states ${ }^{6}$ by major development agencies, endowed with great potential to develop its political and macroeconomic framework. ${ }^{7}$ This is one reason why Tanzania has been a major beneficiary of foreign aid in the past two decades. Still, the developmental indices in Tanzania depict a consistently low social, political and economic performance. ${ }^{8}$ Stand-alone as well as aggregate indicators measuring one or several dimensions of national development show that there is some, but slow and incremental progress. ${ }^{9}$ By the early nineties, Tanzania was one of the leading countries in consistency and spread of liberalisation policies (World Bank 1994) — all the more remarkable given the socialist background of the country. However, the growth rates remained relatively modest and lower than the population growth, at about $3 \%$ yearly

\footnotetext{
5 Unlike many other African countries, such as for instance Zambia, which experienced serious social unrest and upheaval in protest to the Structural Adjustment Programmes (see Rakner 2003).

${ }^{6}$ For a critical discussion of the construction of Africa's 'governance' states see Harrison 2004 .

7 See in particular Adam et al. (1994) or World Bank (2000) for detailed reports and analyses on the levels, composition and impact of foreign aid to Tanzania, which were affected by disillusionment (especially on behalf of bi-lateral donors) and sanctions (on behalf of multi-lateral donors) in the early eighties, but regained a high status amongst all donors in the nineties.

8 As an indication, the Human Development Index 2002 ranks Tanzania in the category 'Low Human Development' on Rank 162 (out of 177). The growth rate of Tanzania between $1975^{-2002}$ averaged $0.6 \%$, and $0.7 \%$ between $1990-2002$, with a GDP per capita of 580 PPP USD in the year 2002 (which is also the year of highest value between 1975-2002).

9 These and further inferences can be drawn from Table 2 'Development and Governance Indices' of Tanzania (see below).
} 
(World Bank 2004), with serious technological and resource gaps remaining (UNCTAD 2003: 67-88). In the period between 2000 and 2006, the GDP grew on average around $6 \%$, which is a respectable growth rate (World Bank 2007; The United Republic of Tanzania 2008: 10).

A defining aspect of Tanzania's national economy is the proportion of foreign aid as part of the national budget. As Table 2, below, shows, Tanzania is a highly aid-dependent country, ${ }^{10}$ with aid levels oscillating around $20 \%$ of GDP in the late eighties, and since gradually dipping down to around $10 \%$, with foreign aid still constituting nearly half of the government budget.11 In spite of favourable political conditions, foreign assistance and the structural reforms aimed at increasing the capacity of the public sector and the economy, various measures of governance indicate that Tanzania still ranks not only amongst the poorest (certainly at the time of the case-study of 2003), but also amongst the most corrupt countries in the world. ${ }^{12}$ The governance challenges in terms of socio-economic outlook are summed up in the 2000-2008 Mid-term Millennium Development Goal Report on Tanzania:

Although for 2007/08 many indicators are less gloomy compared to (say) the early to mid-199os, the country seems unlikely to meet many of the targets

10 Tanzania clearly conforms with Brautigam's succinct definition of aid dependency, namely "a situation in which a country cannot perform many of the core functions of government, such as operations and maintenance, or the delivery of basic public services, with foreign aid funding and expertise" (Brautigam 2000: 9). For concepts and analyses of aid dependency, see Brautigam 2000: 9-15 or Brautigam/Knack 2004.

11 In 2006, the Official Development Assistance to Tanzania amounted to USD 46 per capita, which is just under the Sub-sahara African average of USD $5^{2}$ of the same year (World Development Report 2009: 359, Table 4 'Trade, Aid and Finance'). The average GNI per capita of Tanzania in the same year was USD 400 (World Development Report 2009: 353, Table 1 'Key Development Indicators'). Even within international organisations, this is not seen to be a positive feature. Note, for instance, an official UNCTAD of 2003 document that argues that "[a]id dependency coupled with lack of domestic capabilities makes development difficult to sustain. Perhaps the least desirable outcome is to channel foreign support in an erratic and unpredictable manner through institutions that lack the capabilities, incentives, and structures to be effective. That seems to have been the case in Tanzania" (UNCTAD 2003: 78). Albeit less polemically than for instance Moyo (2008) or Easterly (2006), a growing body of literature elaborates perverse and systemic effects of aid dependency over time, namely that "large amounts of aid may reduce local ownership, accountability and democratic decision-making, while fragmenting budgets and lowering tax effort" (Brautigam 2000: 1; see also Brautigam/Knack 2004).

12 According to Transparency International's Corruption Perceptions Index, Tanzania was on rank 73 out of 85 in 2002, and on rank 92 out of 133 in 2003. The changes in ranking indicate the relative position and methodological adjustments. Hence, the absolute rank is less revealing than the rather intuitive confirmation of widespread corruption in Tanzania (see also Table 2 'Development and Governance Indicators for Tanzania', below). For more information see the Corruption Perceptions Index under 'Surveys' at www.transparency.org. 
by 2015 if the country does not scale up human and financial resources input, with keen attention to effective use of resources, including foreign aid as well as raising domestic resource mobilization effort (The United Republic of Tanzania 2008: 10).

Frequent and indeed routine statements negatively correlating poverty reduction and national development with corruption can be found in some of the most central policy document on Tanzania, as will be shown further down. As can be drawn from the statistics of the DAC/OECD (2010), the allocation of foreign aid earmarked specifically for governance reforms in Tanzania oscillates around 4\% (in 2007) of total foreign aid by DAC countries and multi-national organisations. Not a stupendous amount, but substantial when one takes, firstly, the growing trend in aid modalities towards budget support in to account, with sectoral or programmatic allocation waning in importance; and secondly, when putting the absolute figures in relation with the budget of Tanzania.

In this context, aid allocations tied to the measurement of institutional quality, i.e. governance and anti-corruption, play an important role. In the wake of the increasingly frequent and aid-allocation-defining quantitative definitions of corruption and governance, the past decade has also seen their numerical mapping. In Table 2, below, key indicators are compiled to provide an insight into the most important trends with regard development, governance and corruption in Tanzania, as produced by such aggregate measures. Where the data was available, Table 2 is split into the two years in which the case-studies were undertaken to allow for a very rough comparison between 2003 and 2009/10. The years have been chosen to facilitate a comparison between the two sets of research findings. However, as the available data does not always correspond to the years in question, figures from 2005 have also been included, as they a) usually draw on statistics of the year 2003 (this is also a statement on the time-lag and relative content of such indices and statistics), and b) to facilitate the use of the table as an illustration of trends rather than a set framework. Notable is perhaps also the fact that although I endeavoured to use the same sources for each figure for more transparent comparison, it proved surprisingly difficult to find the same information in reports of different years. The 'messiness' of Table 2 hence also allows some inference with regard to the representation of a clear, unambiguous representation through such neat indices and figures - a neatness that immediately crumbles when seeking to compare even same data over time with some level of precision. 
Table 2: Development and Governance Indicators for Tanzania

\begin{tabular}{|c|c|c|c|c|}
\hline \multicolumn{5}{|c|}{ DEVELOPMENT INDICATORS } \\
\hline \multirow[t]{2}{*}{ Index/Year } & Sources from & Sources from & \multicolumn{2}{|c|}{ Latest Sources } \\
\hline & 2003 & 2005 & 2009 & 2010 \\
\hline Population & Approx. 34.5 million ${ }^{13}$ & $\begin{array}{l}\text { Approx. } 35 \cdot 9 \\
\text { million }^{14}\end{array}$ & - & $\begin{array}{l}\text { Approx. } 42 \\
\text { million }^{15}\end{array}$ \\
\hline GNI p/c (USD) & $270^{16}$ & $290^{17}$ & - & $440^{18}$ \\
\hline $\begin{array}{l}\text { GDP p/c \% growth } \\
\text { Annual real GDP } \\
\text { growth }\end{array}$ & $\begin{array}{l}2.3^{19} \\
4.3^{20}\end{array}$ & $\begin{array}{l}3.5 \%^{21} \\
5 \cdot 1^{22}\end{array}$ & - & $\begin{array}{l}4.4^{23} \\
6.8^{24}\end{array}$ \\
\hline $\begin{array}{l}\text { ODA (USD p/c) } \\
\text { Aid dependency as \% } \\
\text { of GNI }\end{array}$ & $\begin{array}{l}31^{25} \\
\text { 2003: } \mathrm{n} / \mathrm{a} \\
\text { 2000: } 11.6 \% \text { of } \mathrm{GNI}^{26} \\
\text { 2001: } 13,3 \% \text { of } \mathrm{GNI}^{27}\end{array}$ & $35^{28}$ & $\begin{array}{l}68^{29} \\
2007: 17.4 \% \text { of } \\
\mathrm{GNI}^{30} \\
10.2 \% \text { of } \mathrm{GDP}^{31}\end{array}$ & $\mathrm{n} / \mathrm{a}$ \\
\hline
\end{tabular}

13 World Development Report 2003 (World Bank 2003: 235), giving the figures for 2001.

14 World Development Report 2005 (World Bank 2005: 257), giving the figures for 2003.

15 World Development Report 2010 (World Bank 2010: 379), giving the figures for 2008.

16 World Development Report 2003 (World Bank 2003: 235), giving the figures for 2001 (Data refer to mainland Tanzania only).

17 World Development Report 2005 (World Bank 2005: 257), giving the figures for 2003 (data refers to mainland Tanzania only).

18 World Development Report 2010 (World Bank 2010: 379), giving the figures for 2008 (data refers to mainland Tanzania only).

19 World Development Report 2003 (World Bank 2003: 235), giving the figures for 2000-2001.

20 African Economic Outlook 2002/2003: 379 ("Statistical Annex"), giving the average over 1995-2001.

21 World Development Report 2005 (World Bank 2005: 257), giving the figures for 2002-2003.

22 African Economic Outlook 2004/2005: 499 ("Statistical Annex"), giving the average over 1996-2003.

23 World Development Report 2010 (World Bank 2010: 379), giving the figures for 2007-2008.

24 African Economic Outlook 2009: 151 ("Statistical Annex"). Available under: http:// www.oecd.org/dataoecd/10/1/42724007.pdf (last accessed 21 April 2010), giving the average over 2002-2008.

25 World Development Report 2003 (World Bank 2003: 241), giving the figures for 2000.

26 World Development Indicators 2009: 378, figures for 2000.

27 World Development Report 2004 (World Bank 2004: 261), giving the figures for 2001.

28 World Development Report 2005 (World Bank 2005: 262), giving the figures for 2002.

29 World Development Report 2010 (World Bank 2010: 387), giving the figures for 2007.

30 World Development Indicators 2009 (World Bank 2009: 378), giving the figures for 2007.

31 In 2007/08 approx. 44\% of realised expenditure was ODA (see African Economic Outlook (AEO 2009-Tanzania, section 'Fiscal Policy'). This figure includes loans, grants and proceeds from debt relief. According to the AEO, the government of Tanzania has targeted a reduction of donor dependence to $34 \%$ in its 2008/og. For the country statistics see AEO under "country statistics". 
Table 2 (cont.)

\begin{tabular}{|c|c|c|c|c|}
\hline \multicolumn{5}{|c|}{ DEVELOPMENT INDICATORS } \\
\hline \multirow[t]{2}{*}{ Index/Year } & Sources from & Sources from & \multicolumn{2}{|c|}{ Latest Sources } \\
\hline & 2003 & 2005 & 2009 & 2010 \\
\hline $\mathrm{HDI}^{32}$ & $\begin{array}{l}\text { Low Human } \\
\text { Development (Rank } \\
160 \text { out of } 175 ; \\
\text { Score } 0.400)^{33}\end{array}$ & $\begin{array}{l}\text { Low Human } \\
\text { Development } \\
\text { (Rank } 164 \text { out } \\
\text { of } 177 \text {; Score } \\
0.418)^{34}\end{array}$ & $\begin{array}{l}\text { Medium Human } \\
\text { Development } \\
\text { (Rank } 151 \text { out of } \\
\text { 182; Score o.530) }\end{array}$ & $\mathrm{n} / \mathrm{a}$ \\
\hline
\end{tabular}

\section{GOVERNANCE INDICATORS}

World Governance See chart below

Index

\begin{tabular}{|c|c|c|}
\hline $\begin{array}{l}\text { African Governance } \\
\text { Index }{ }^{36}\end{array}$ & $\begin{array}{l}\text { 2003: Rank } 20 \text { out of } 53 \\
\left.\text { (Score: } 5^{2.42}\right)^{37}\end{array}$ & $\begin{array}{l}\text { Rank } 12 \text { out of } 53 \\
(\text { Score: } 59.24)^{38}\end{array}$ \\
\hline Freedom House ${ }^{39}$ & 2003: Partly Free & 2009: Partly Free \\
\hline $\begin{array}{l}\text { Global Integrity } \\
\text { Index }\end{array}$ & $\begin{array}{l}\text { 2003: n/a } \\
\text { 2006: Overall Score } 59 \text { ("Very Weak") }{ }^{40}\end{array}$ & $\begin{array}{l}\text { n/a } \\
\text { 2007: Overall Score 6o ("Weak") }{ }^{41}\end{array}$ \\
\hline $\begin{array}{l}\text { Corruption Percep- } \\
\text { tions Index (CPI })^{42}\end{array}$ & $\begin{array}{l}\text { 20o3: Rank } 92 \text { out of } 133 \\
\text { (Score: } 2.5)^{43}\end{array}$ & $\begin{array}{l}\text { 2009: } 126 \text { out of } \\
\text { 18o (Score: } 2.6)^{44}\end{array}$ \\
\hline
\end{tabular}

(Source: Compiled by the author)

$32 \mathrm{http}: / /$ hdrstats.undp.org/2008/countries/country_fact_sheets/cty_fs_TZA.html (last accessed 21 April 2010).

33 Human Development Report 2003 (UNDP 2003: 240), giving the figures for 2001.

34 Human Development Report 2005 (UNDP 2005: 222), giving the figures for 2003.

35 Human Development Report 2009 (UNDP 2009: 173), giving the figures for 2007.

36 See further down in this section for an elaboration on the Mo Ibrahim Index of African Governance.

372009 Ibrahim Index of African Governance, year 2003. Full dataset including figures from 2000 to 2007 available under http://www.moibrahimfoundation.org/en/section/ the-ibrahim-index/scores-and-ranking (last accessed 21 April 2010).

382009 Ibrahim Index of African Governance for Tanzania, giving the figures for 2007 (see http://www.moibrahimfoundation.org/en/media/get/20091004_tanzania.pdf, last accessed 21 April 2010). Full dataset including figures from 2000 to 2007 available under http://www.moibrahimfoundation.org/en/section/the-ibrahim-index/scores-and-ranking (last accessed 21 April 2010.

39 For full rankings see "Freedom in the World Historical Rankings" under http://www .freedomhouse.org/template.cfm?page $=5$ (last accessed 21 April 2010).

40 Tanzania Integrity Scorecard for 2006 available under http://www.globalintegrity .org/reports/2006/tanzania/scorecard.cfm (last accessed 21 April 2010).

41 Tanzania Integrity Scorecard for 2007 available under http://report.globalintegrity .org/Tanzania/2007/scorecard (last accessed 21 April 2010).

42 The CPI is measured on a scale of $0-10$, with $10=$ not corrupt, $0=$ highly corrupt.

43 Corruption Perception Index 2003, giving the figures for 2003.

44 Corruption Perception Index 2009, giving the figures for 2009 . 
The ratings, numbers and indices listed in Table 2 not only situate development, governance and corruption in Tanzania, they are of key importance for defining the image of Tanzania in developmental terms. For all their strengths and weaknesses, ${ }^{45}$ the rankings state the slow but steady progress of Tanzania's developmental and governance performance in the past decade. This is particularly apparent in the annual real growth rates and in the leap from the HDI category 'Low Human Development' to 'Medium Human Development', representing improvements in the measured social and economic dimensions. But in spite of observable improvements, the indicators outline a profile of low social and economic development, weak public institutions, with concomitant weak accountability institutions and high levels of corruption. Drawing from these rankings, Tanzania can be described as a 'typical' but hopeful African country, which, yes, is characterised by underdevelopment and corruption, but gradually making its way up the rankings.

However, one critique of such indices is that they are all on a highly aggregate level, severely curtailing their significance with regard to national and local contexts. In other words, the overall rankings of the aggregate and composite indicators have little explanatory power with regard to the quality and changes in specific sectors of a nation. ${ }^{46}$ This becomes particularly apparent when one takes the effort to break the scorings down, that make more differentiated statements on key governance dimensions. The following chart of the World Governance Index (Figure 4, below) disaggregates the score according to year and dimension. The chart shows quite clearly the improvement as well as the uneven dynamics of Tanzania's 'performance' (in the survey's terminology) over the past decade; i.e. the dynamics of social and political change over time.

\footnotetext{
45 Apart from the inherent methodological problems of aggregate indices, see Heller (2009) for an overview and critical assessment of corruption indices, see UNDP (2008) for an overview over governance indices, see Arndt/Oman (2006) for a critical assessment of governance indices.

46 A more nuanced approach to quantitative analysis of corruption has been pioneered by no-one less than Daniel Kaufmann, the pioneering former head of the World Bank Institute and leading governance analyst. He was formative in establishing the recently developed Actionable Governance Indicators Portal, which "has been developed in response to the increasing demand for governance indicators that could help design specific reforms and monitor their impacts. The portal consolidates information on actionable governance indicators, provides a one-stop-shop platform to navigate these indicators and their documents and offers customized tools for data management, analysis and display" (see https:// www.agidata.org/main/AboutAGI.ashx; last accessed 27 October 2009).
} 
TANZANIA

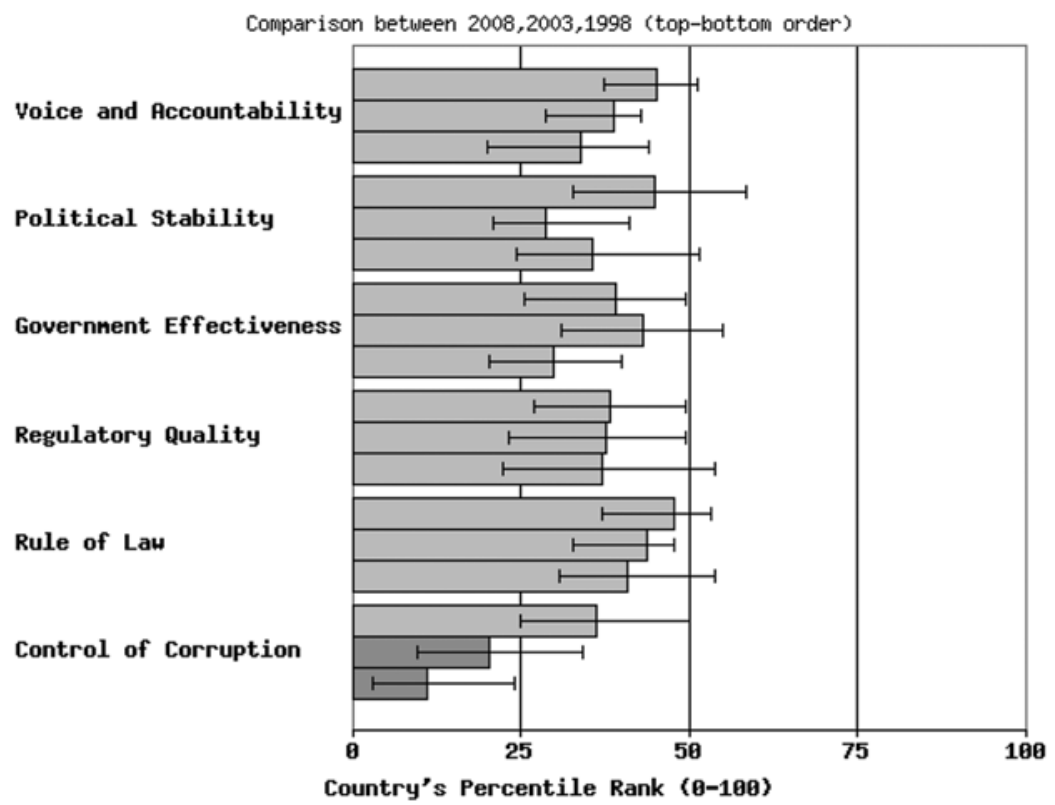

Source: Kaufmann D., A. Kraay, and M. Mastruzzi 2009: Governance Matters VIII : Governance Indicators for 1996-2008

Note: The governance indicators presented here aggregate the views on the quality of governance provided by a large number of enterprise, citizen and expert survey respondents in industrial and developing countries. These data are gathered from a number of survey institutes, think tanks, non-governmental organizations, and international organizations. The UGI do not reflect the official views of the Uorld Bank, its Executive

Directors, or the countries they represent. The WGI are not used by the World Bank Group to allocate resources.

Figure 4: World Governance Index (Tanzania) 1998-2008

The World Governance Indicator quite explicitly seeks to articulate differences over time within countries, not merely between countries, in an effort to provide a more nuanced representation of governance. According to this representation, the quality of governance, as measured in the six dimensions, has all in all improved over the past seven years. Notably, the dimension with the greatest improvement is control of corruption-a dimension that the case-studies in the following chapters will be dwelling on in a more emic approach. This also fits in with the increased attention that donors have been paying to the control of corruption, funding and implementing sweeping institutional, legal and regulatory reforms.

There is a general trend observable of global indices to incline towards greater disaggregation and supplementary qualitative framing. One important source of governance assessments is the detailed information 
contained in the Integrity Indicators Scorecard of the Global Integrity Index (2008). The Global Integrity Index measures and ranks countries worldwide in a neat digit. ${ }^{47}$ However, it is flanked by the Reporters' Notebook (see further down), which provides an in-depth commentary on relevant political, economic and social processes, and by the Integrity Indicators Scorecard, which allow assessments of individual categories and sub-categories of the Global Integrity Index. ${ }^{48}$ Table 3, below, shows the latest scores and rankings of the Scorecard on Tanzania.

As Table 3 indicates, in the ranking of the Global Integrity Scorecard the anti-corruption efforts of Tanzania actually fare very badly, contrary to the relative progress highlighted in the World Governance Indicators. In this sense, the statements on governance and corruption by such global indices do now provide a far more diverse map of corruption and

Table 3: Tanzania Integrity Index Scorecard $2007^{49}$

\begin{tabular}{lcl}
\hline DIMENSION & SCORE & RANKING \\
\hline Oversight and Regulation (Cat. V) & & \\
\hline National Ombudsman & 71 & Moderate \\
Supreme Audit Institution & 68 & Weak \\
Taxes and Customs & 86 & Strong \\
State-Owned Enterprises & 67 & Weak \\
\hline Anti-corruption and Rule of Law (Cat. VI) & & \\
\hline Anti-Corruption Law & 100 & Very strong \\
Anti-Corruption Agency & 59 & Very weak \\
Rule of Law & 59 & Very weak \\
Law Enforcement & 46 & Very weak \\
Score Anti-Corruption and Rule of Law & 66 & Weak \\
\hline
\end{tabular}

(Source: Global Integrity) ${ }^{50}$

47 See Table 2 'Development and Governance Indicators in Tanzania', above.

48 There are six categories of Integrity Indicators in all, namely (i) Civil Society, Public Information and Media, (ii) Elections, (iii) Government Accountability, (iv) Administration and Public Service, (v) Oversight and Regulation, and (vi) Anti-corruption and Rule of Law.

49 At the time of writing (March 2010) there were no more recent scorecards of Tanzania available. For the Scorecard and further information see http://report.globalintegrity. org/Tanzania/2007/scorecard (last accessed 25 March 2010).

50 See under http://report.globalintegrity.org/Tanzania/2007/scorecard (last accessed 25 March 2010). 
governance-dimensions, which also allow for statements over time. Articulated in brute numbers, the ranking of countries is seemingly unambiguous. Dipping under the surface, it is possible to draw a multifaceted range of articulations and statements from these rankings, with which new discourses are shored up and established ones legitimised.

The same pattern is recognisable on a regional level, embodied by the much-noted introduction of the Mo Ibrahim African Governance Index, a new governance index, funded by an African entrepreneur (and, in addition, is coupled to a 'Leadership Prize'), and designed with all the authority of the Harvard Kennedy School of Government. Notable is here not only the African origins (which in addition); notable is the omission of anti-corruption as a proxy for the quality and the outcome of governance processes. The Ibrahim Index assesses governance as captured in the dimensions Safety and Rule of Law; Participation and Human Rights; Sustainable Economic Opportunity; and Human Development..$^{51}$ Again, this index is characterised by sophisticated data and graphical breakdowns, allowing for comparisons over time, between regions or within categories. Here, Tanzania also demonstrates a notable improvement, inching its way up the scores in the past few years. Table 4 depicts the relative progress of Tanzania in the past decade.

Table 4: Mo Ibrahim Index of African Governance: Figures for Tanzania (2000-2007)

\begin{tabular}{lllllllll}
\hline TANZANIA & 2000 & 2001 & 2002 & 2003 & 2004 & 2005 & 2006 & 2007 \\
\hline Ranking & 14 & 17 & 18 & 20 & 17 & 15 & 15 & 12 \\
Score & 53.5 & 53.15 & 53.06 & 52.42 & 53.76 & 55.89 & 57.03 & 59.24 \\
\hline
\end{tabular}

(Source: Table compiled by author; data drawn from the Mo Ibrahim Index of African Governance $)^{52}$

51 The Ibrahim Index assesses governance against 84 criteria, making it the most comprehensive collection of qualitative and quantitative data that measures governance in Africa. The criteria are divided into four main categories and 13 sub-categories. The indicators that make up the sub-categories are based either on official data or expert assessment (see the website under http://www.moibrahimfoundation.org/en/section/the-ibrahimindex; last accessed 25 March 2010). In 2009, 53 African countries were included in the survey.

52 All information available under http://www.moibrahimfoundation.org/en/section/ the-ibrahim-index (last accessed 25 March 2010). 
Summing up the aggregate surveys on development and governance, it can be observed that a certain sophistication of the measurement of governance is taking place. Whereas the first governance indices were relatively crude and standardised, with the explicit aim to quantify 'governance' as neatly as possible, currently governance indicators are being elaborated or designed to allow more profiled and nuanced markers-albeit numerically reduced. Viewed through this discourse, Tanzania emerges as a country characterised by a rather poor governance performance in world-wide comparison, ranking in the bottom quarter of both development as well as governance indicators. However, the assessments over time all show a steady improvement of Tanzania's governance performance. It is not my purpose to deconstruct the 'truth' of this performance. What I do want to profile, however, that judged by these surveys, the institutional and regulatory framework of Tanzania has undergone quite significant changes over the past decade. Contrary to the Africa pessimism, positive (in terms of the measured dimensions) change has been documented in Tanzania in the past decade.

Still, in spite of the more differentiated and longitudinal surveys available today, the scores represent either global or continental topographies of governance and corruption that are necessarily standardised. This leads to highly condensed, categorical statements, i.e. either as a naked rank or score, or as in bland and non-descript qualifications such as 'weak' or 'partly free'. However, there is a rich body of articulations that make dispersed as well discursively more formed statements on contexts of corruption in Tanzania. Although these statements cannot necessarily be directly related to the indices, following often completely different rationales and intentions, the following section seeks to profile this contextual landscape in sharper relief, by assembling country-specific statements and articulations on governance and corruption in Tanzania.

\section{Qualified Views of Corruption in Tanzania}

Only in the past decade have more measurement tools and data on corruption been available - a new field of empirical data that can also be seen from the relatively recent introduction of most of the indicators above. The same can be said of country-specific surveys and assessments, which in general do not aim to rank and compare, but to provide a more qualitative assessment of corruption in a given country. A distinction can be made between surveys and reports that are mandated by the government 
and form part of a national anti-corruption strategy, and surveys and reports that are mandated and/or are carried out by national or international non-governmental organisations. In this section, the most important elements and statements of these qualitative surveys and reports will be listed schematically, in a chronological order-which should also make the quickened frequency and types of such surveys visible. Also, where present, statements on corruption in the construction industry and public procurement will be emphasised, as this is the area in which the case-studies undertaken in the following two chapters are situated.

\subsection{The Warioba Report (1996)}

Tanzania is in fact an interesting example, for as early as 1996 the government under President Benjamin Mkapa established a commission endowed with investigative powers to report on corruption in Tanzania (The United Republic of Tanzania 1996a). The report, popularly known as the Warioba Report, named after the renowned chair of the Presidential Commission, came up with detailed and damning findings on types and extent of corruption in Tanzania. Essentially, they distinguished between corruption due to poverty and low incomes (The United Republic of Tanzania 1996a: 4), and corruption by persons in authority. It is worth quoting the passage on this type of corruption in original:

The second problem which is more serious is that even if the people know their rights and therefore refuse to pay for them by exposing the corrupt elements instead, they appear to have despaired because the leaders in whom they had placed trust and who they expected to be their refuge, have themselves become engulfed by corruption. The Tanzania public has been reluctant to expose those who solicit and receive bribes because of a lack of clean and responsible leadership in the government organs concerned like the police, judiciary, the Anti-Corruption Bureau and the Department of National Security. Thus the greatest task before the Government itself, the Parastatals and indeed the political parties, is to clean up the leadership currently in power. After that it will be necessary to take steps to develop a cadre of leadership which is genuinely committed to fighting the scourge of corruption at all levels by taking action against all who are exposed. By so doing, we shall have restored public confidence in the state apparatus and therefore speed the eradication of corruption in the country (The Government of Tanzania 1996a: 15; emphases in original).

The report was at the time and has been since widely acclaimed for its astute and impartial assessment of corruption in Tanzania. The report went very far, to the extent of incriminating and naming particular senior 
public officials. However, as Chapter 3, below, will discuss in more detail, essentially there was political inertia after the initial stir of the publication. In any case the Warioba Report is still widely cited and known, providing a very detailed description of types and extent of corrupt practices within public agencies.

\subsection{State of Corruption in Tanzania Annual Report (2001)}

With the technical and financial support of the UNDP, it was decided that the Tanzanian National Anti-Corruption Strategy and Action Plan (NACSAP) of 1999 (see section further down) should be systematically monitored and evaluated by a system of Annual Reports. In March 2001 the Prevention of Corruption Bureau ${ }^{53}$ invited proposals from independent institutions and in late 2002 the first State of Corruption in Tanzania Annual Report 2001, was published, prepared by a consortium between the Economic and Social Research Foundation (ESRF) ${ }^{54}$ and an anticorruption organisation called Front Against Corrupt Elements in Tanzania (FACEIT). ${ }^{55}$ The data and information collected and analysed in the report is intended as a prime policy tool in the fight against corruption. Hence, its TORs include the following specific objectives:

- to provide an information base for future anti-corruption policies

- to monitor and assess the state of corruption in Tanzania after adoption of NACSAP and sector-specific action plans in Ministries and key departments (MDAs)

- to review and collect information on the implementation of sector specific action plans (ESRF/FACEIT 2001: 6)

Not endowed with the same investigative powers as the Warioba Commission, the report necessarily relies more on a multi-pronged methodology of desk-research, individual and focus group interviews as well as workshops with key professionals to capture the dynamics of corruption. Using the recommendations of the Warioba-Report and NACSAP as a baseline, the report compares the measures taken with the actual results in the prime sectors. The sectors analysed are the institutional framework

53 For an overview over the mandate of PCB see Chapter 3 (Section 3.2) and Chapter 4 (Section 3.4), below.

54 Acronym for Economic and Social Research Foundation.

55 Acronym for Front Against Corrupt Elements in Tanzania, an organisation which in 2003 was in fact the only vocal interest group against corruption in Tanzania. This had changed completely in 2010, with organisations such as ForDIA taking on advocacy activities in a very professional manner. 
(Chapters II-IV), the Sector Ministries (Chapter V), the Local Government Authorities (Chapter VI), the Financial Sector (Chapter VII), Public Procurement (Chapter VIII), and lastly, the Mass media (Chapter IX). The focus group discussions were held with Lawyers, Auditors and representatives of the construction industry. Although the quality of the report and in particular the survey methodology is rather uneven, it documents both systemic and incidental cases of corruption.

In all areas, corruption remains a serious problem, with the surveyed citizens, respondents and focus groups reporting relatively frequent experiences with corruption, as well as providing detailed information on prevalent corrupt practices and regulatory problems (due to both overregulation as well as under-regulation). The two areas in which corruption are reported to be most expansive is the Local Government Authorities ${ }^{56}$ and Public Procurement, and even more so in the interface of the two. The report states with unusual candour that

[p]rocurement of goods and services (supplies of materials and works contracts [sic] particularly in roads contracts) is one area where corruption is rampant. Councillors flout tender regulations in selecting contractors for roads works. This has often led to inflated costs, poor works quality and delayed completion [...]. These practices are perceived as grand and systemic corruption in the local authorities (ESRF/FACEIT 2001: 84).

On a national level similar practices are documented across public authorities, ranging from Lands to Communication, where both incidental as well as routine practices of corrupt collusion, embezzlement, extortion or just plain bribery are reported. According to the Annual Report on the State of Corruption 2001, most of these practices have not changed greatly since the publication of the Warioba report, in spite of governmental commitments to implement its recommendations. A further problem, again already observed and condemned by the Warioba report, is a legalised form of political corruption, which is known as 'takrima' (Swahili for gift or favour). The law on 'takrima', introduced in 2000, allows parliamentary candidates during elections to give certain benefits ('takrima') to voters as an inducement to gain their votes, evidently a practice that borders on bribery. ${ }^{57}$

\footnotetext{
56 See also the Report on Corruption in Local Government Authorities (2005) further down.

57 This law was outlawed in a High Court ruling in 2006, after legal rights organisations had challenged its legality in a law-suit (see under http://news.bbc.co.uk/2/hi/ africa/4941672.stm; last accessed 25 March 2010).
} 
In large parts, the tone of the report is very conciliatory, in spite of some interesting, specific and significant findings. These are mainly hidden in the individual chapters and the Appendices on the Focus Group Discussions. The conclusions of the report are particularly weak, summing up some 200 pages in a mere two pages, much of which is devoted to describing reforms undertaken, rather than an analysis of the problems. It does stress, however, the importance of political will. More specifically, it states that the "findings of this report reveal that there is still a lot to be done by the Government to demonstrate a clear political commitment in the war against corruption" (ESRF/FACEIT 2001: 160). Perhaps more graphically, a summary statement from the Auditors Workshop that forms part of this report underlines this point:

It was lamented that though the President [Mr Benjamin Mkapa] has good intentions concerning the fight against corruption, over the years, things are turning out to be worse and worse. Leaders do not lead the way and have been one of the reasons for the worsening situation. Takrima was felt to be anathema to this fight. The meeting stressed the need to be serious and sincere at all levels of leadership, otherwise things will remain the same. ${ }^{58}$

Although the report was announced as an annual publication, for the next six years no further annual report was commissioned, mainly due to the lack of funding forthcoming by donors. ${ }^{59}$ The non-materialisation of an annual report, however, also shows a lack of commitment on the side of the government in these years. Only with the implementation of NACSAP II and funding from Danida was the project 'annual report' and improvement of official data on corruption for planning purposes tackled again. In September 2009, the second Annual State of Corruption and Governance Report 2009 was presented to the public (see Section 3.9, below).

\subsection{National Strategy for Growth and the Reduction of Poverty (2005-2010) (MKUKUTA) $)^{60}$}

Articulations on corruption, however, are not only limited to corruption-specific reports. Corruption in Tanzania is routinely articulated in

58 Summary Records from the Auditors Workshop, held on 1 November in Dar Es Salaam, Annex V 'Minutes of Constructors Workshop' of the Annual Report of the State of Corruption in Tanzania, (ESRF/FACEIT 2001: 22).

59 This is not least due to the disenchantment of donors on the quality of the Report (personal communication with multi-lateral donors in February and March 2003).

60 The Strategy is far better known under its Swahili acronym MKUKUTA, which stands for 'Mkakati wa Kukuza Uchumi na Kupunguza Umaskini Tanzania'. 
conjunction with and in reference to national development, economic growth and in particular poverty-reduction, as the next section illustrates. These are particularly dominant in development policies published by the government. The most important of these is MKUKUTA, a largely donorfinanced national framework guiding social and economic policies for poverty reduction. To substantiate and anchor developmental priorities in society, development needs were assessed in nation-wide stakeholder's consultations. In this context, corruption was shown to be a concern of citizens. In a survey conducted by the National Bureau of Statistics, the respondents showed

great anxiety on issues of governance and corruption. These were stated as red tape, harassment by tax collectors and town/city officials, corruption, violent crime, un-enforceable contracts, weak courts, band norms or customs, perverse external influence on values, 'unfulfilled promises' made by their leaders or representatives, nepotism, favouritism in giving micro-credit service [...]. Some expressed doubts whether their problems or grievances were ever forwarded to higher authorities for action (MKUKUTA 2005: 21).

Interesting here is the range of practices and issues identified as being relevant to governance and corruption, from distorted value-structures to bureaucratic discretion. It is also quite revealing with regard to the lack of trust citizens seem to have in formal accountability structures.

Further key policy documents, all relating to MKUKUTA, are much in the same vein as some of the operational statements encountered in the discourse of good governance. For instance, in one of the annual assessment documents, the so-called cluster-strategies of the chapter on governance and accountability give an idea just how, firstly, linkages between key development terms (poverty-reduction, corruption, equity, etc.) are constructed, and, secondly, just what an enormous field of intervention is being (re-)produced by such policy documents:

The cluster has seven goals, namely:

i. Ensure that structure and systems of governance as well as the rule of law are democratic, participatory, representative, accountable and inclusive;

ii. Equitable allocation of public resources with corruption is effectively addressed;

iii. Effective public service framework is in place to provide foundation for service delivery that support poverty reduction;

iv. Rights of the poor and vulnerable groups are protected and promoted in the justice system;

v. Reduction of political and social exclusion and intolerance; 
vi. Improvement of personal and material securities, reduced crime, eliminate sexual abuse and domestic violence; and lastly to

vii. Promote and enhance national cultural identities" (IMF 2008: 55).

\subsection{Corruption in Local Authorities in Tanzania (2005)}

Beyond surveys on a national level, it was recognised quite early on that corruption in local government authorities (LGAs) is a pertinent problem not captured by national legislation. Also, there was still very little empirical information available on corrupt practices in LGAs. A comprehensive survey mandated by the PCB and the UNDP and undertaken by an eminent professor seeks to address this lacuna, and comes to following conclusion:

On the whole corruption [...] remain[s] a daunting challenge not only for LGAs but for the whole country. [...] Rigid, bureaucratic, unknown procedures and unresponsive bureaucrats make people believe they would not get the service they deserve without 'oiling the system' or 'wearing long shirt sleeves', i.e. bribing the official. [...] Inadequate poor service delivery, poor working conditions and unattractive working conditions, including lack of working equipment create a conducive environment and temptation for engaging in corrupt practices. However, it is equally true that contradictory and incongruent policy and political statements between the politicians and the LGA technocrats on the one hand and these and the citizens on the other hand fuel perceptions on corruption. [...] The laid down laws, rules and regulations are in place and some are available at LGA offices but are hardly known to LGA officials and citizens which makes compliance ineffective. It seems that the political side of LGAs [elected representatives] is less involved in anti-corruption strategy than the technical side hence making the fight against corruption less effective (Ngware 2005: 111; emphases in original).

The main statements of the report, hence, do not necessarily affirm the view that corruption in Tanzania is diminishing in day-to-day interactions with public officials. Rather, it depicts a landscape in which corrupt practices are systemically produced through uneven institutionalisation of anti-corruption and other governance reforms on the one hand, and entrenched attitudes towards corruption that are reinforced by disempowerment and poverty. However, as the quotes show, the report makes an explicit distinction between the technocratic level and the political level of anti-corruption efforts, indicating that reforms on the technocratic level are technically in place and probably sufficient, but the political will is still very uneven in making these reforms 'live' and effective-political will, as the report discusses and substantiates in some detail, that is not 
merely a result of individual politician's integrity, but of “a deeper culture of popular participation in civic affairs which is only just emerging in Tanzania" (Ngware 2005: 24).

\subsection{Afrobarometer: Perceptions and Experiences of Corruption in Tanzania (2005)}

This survey is an interesting exercise in mapping the experiences and perceptions of Tanzanians on corruption in their country, and it comes up with a number of interesting findings. These are especially interesting as they allow a comparison between the first survey in 2003 and this second survey (2006). I only want to highlight two remarkable findings here: firstly, the survey indicates a trend, namely that between $2003-2005$ personal experiences with corruption as well as perceptions of corruption among public officials have actually declined. ${ }^{61}$ The former is depicted in Figure 5, below, which leads the authors of the survey to conclude that government efforts to curb corruption are showing some success.

According to the Afrobarometer, the perceived degree of corruption associated with public officials has also declined, although it remains on a high level. So,

in $2003,80 \%$ thought that 'some', 'most', 'all' police were involved in corrupt practices, but in 2005 this has dropped to $72 \%$. Likewise, in $200352 \%$ thought that/some/most/all 'elected officials' engaged in corruption, but in 2005 a much lower $38 \%$ think MPs are corrupt, and $44 \%$ say the same for elected local government councilors [sic] (Afrobarometer 2006: 4).

Although this finding is based on interactions with only three public services, it would confirm the improvement of Tanzania's ranking on the CPI and on the various governance indices. However, as Figure 6, below,

61 See Afrobarometer 2006: 5, Figure 4; out of six common interactions with authorities surveyed, three show a reduction (obtaining a permit; obtaining a household service; interaction with police), one remains the same (access to education), and two cannot be compared as they were not included in the 2003 survey (access to health care (see below) and voting). The prevalence of corruption in the police service as well as in the judiciary are shored up by the findings of the Eastern Africa Bribery Index (EABI) 2009 (see section further down): the Tanzanian Police Force (EABI score 62,56) and the Judiciary/Courts (EABI score 61,48) rank highest on the EABI score, ahead of Local Authorities (rank 5) and health care (rank 8). For the full ranking see Eastern African Bribery Index Report 2009: 34 (Table 30 'Tanzania Aggregate Index'). One interesting finding of the Afrobarometer Corruption Survey is that it seems that Tanzanians are most frequently pressured into corruption by health workers (See Afrobarometer 2006: 5,6 (Figure 4 and Figure 5); unfortunately, healthcare was only included in the survey of 2005 , hence not allowing a comparison to the situation in 2003). 


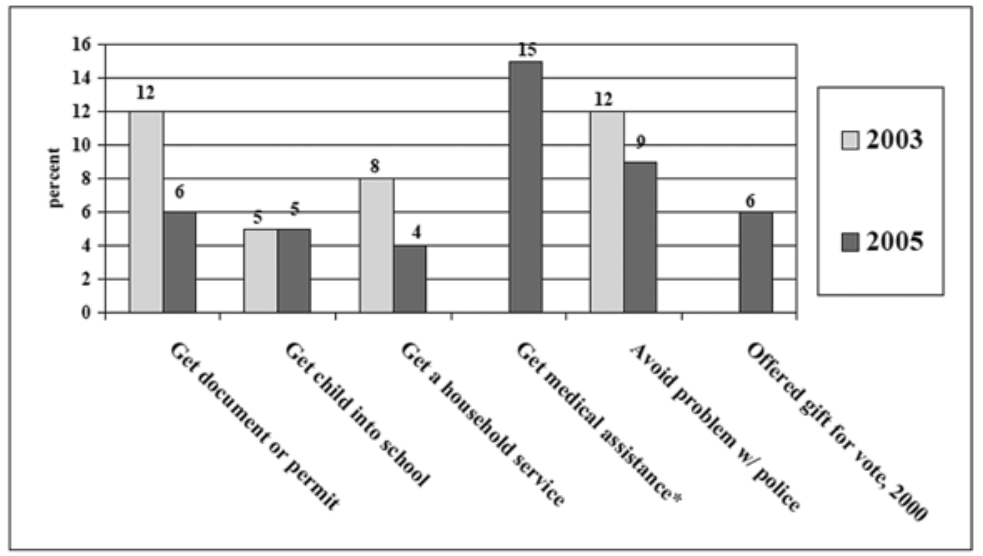

"In the past year, how often (if ever), have you had to pay a bribe, give a gift, or do a favour to government officials in order to: a) Get a document or permit; b) Get a child into school; c) Get a household service (like piped water, electricity or a phone); d) Get medicine or medical attention from a health worker; e) Avoid a problem with the police (like passing a checkpoint or avoiding a fine or arrest)? And during the 2002 election, how often (if ever) did a candidate or someone from a political party offer you something, like food or a gift, in return for your vote?" " (\% yes, i.e., "once or twice," "a few times, " or "often")

*Question not asked in 2003.

(Source: Afrobarometer 2006: 6, Figure 4)

Figure 5: Personal Experience of Corruption 2003-2005

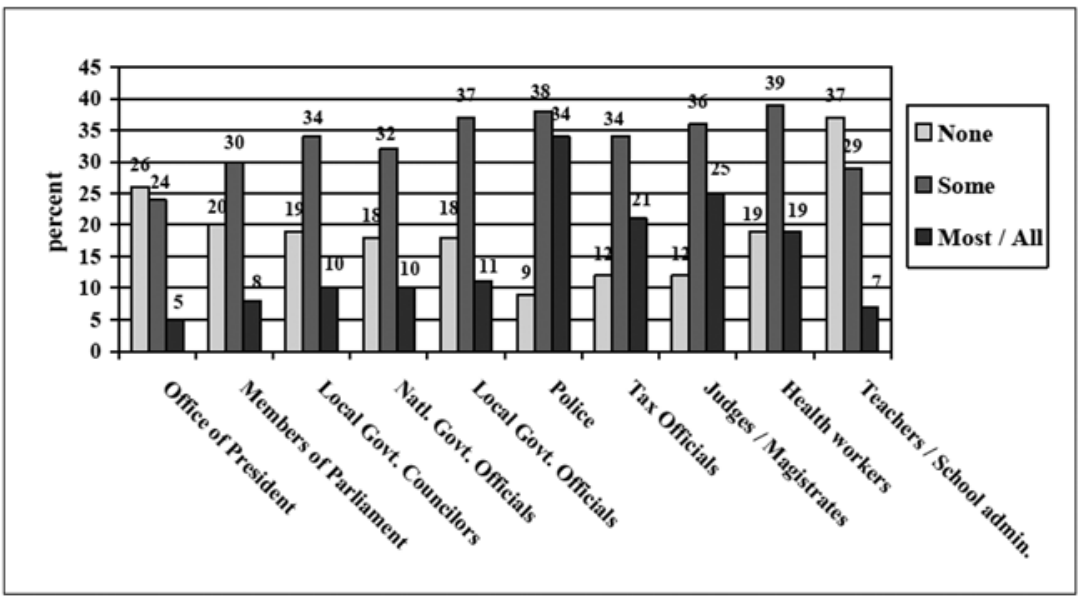

(Source: Afrobarometer 2006: 4, Figure 3)

Figure 6: Extent of Perceived Corruption Amongst Public Officials 
shows, the level of perceived corruption among public officials is still on a relatively high level.

Secondly, addressing a commonly held myth (and one that was discussed under the 'moral economy of corruption' in Chapter 1, above), the surveys find that ordinary citizens' understanding of what constitutes an act of corruption does not differ to the understanding that citizens hold of corruption internationally: "Clearly, Tanzanians for the most part share international perceptions of how public officials are supposed to behave in executing their responsibilities. Traditional cultural practices, whether of gift giving or other varieties, do not, in the eyes of the Tanzanian public, entitle government officials to take advantage of them" (Afrobarometer 2006: 6). This is significant in that it counters statements made for instance by parts of the academic discourse, who seek to emphasise the 'local' or 'socio-cultural' understanding and practice of corruption. It also makes a clear statement on the type of expectations that Tanzanians have of public institutions, namely the impartial provision of public goods.

\subsection{Global Integrity Report: Tanzania-Reporter's Notebook (2007)}

As noted above, part of the Global Integrity Report is a so-called reporter's notebook, where a key informant, such as a journalist, an activist or a researcher, describes in an anecdotal fashion symptomatic incidences illustrating the mechanisms of accountability and integrity in a given country. The reporter for Tanzania in 2007 dwells at length on the largescale corruption scandals that have emerged especially in the wake of privatisation schemes, and links them to the destitution and lack of access to basic resources such as clean water, sanitation or electricity for the large parts of the population, which also pays extortionate rates for unreliable or unprovided services. And yet, according to the reporter:

The power sector drama is just the tip of the iceberg of corruption in Tanzania. [...] A lack of checks and balances in the system is partly to blame. Abuse of power continues to thwart efforts to promote sound governance, while Parliament has proven nearly useless in its oversight role and as a check on executive power. Democratic governance is elusive as powerful and self-interested economic actors gain control over the executive branch and wield its powers to their own advantage. Annual auditing of public funds by the Controller and Auditor General, capacity building for the PCCB, awareness campaigns on corruption, donor-supported governance initiatives as well as the formation of the sector Parliamentary Committee are not effective enough. This is partly due to state capture, a process in which powerful elites from the private sector buy off politicians and bureaucrats to twist 
laws, budgets, projects, policies and regulatory environments in their own interest. The majority of parliamentarians are little more than rubber-stamp legislators, who approve defective plans from the executive branch with little due diligence or scrutiny. Political patronage dilutes governance-building initiatives. Thanks to political stability, there have been no riots to date. But unless a comprehensive effort is made across all branches of government to promote sound governance and integrity in government, Tanzania's infrastructure and resource challenges will be here to stay. ${ }^{62}$

These strong statements paint a grim picture of the decision-making process in Tanzania, which, according to this perspective, is characterised by patronage, abuse of power and impunity. Juxtaposing this conclusion with the some of the findings of the Afrobarometer, there may be need to make a distinction between the decrease in petty corruption, i.e. the corrupt practices citizens encounter in day-to-day interactions with public authorities, and increase grand corruption, which involves senior politicians and public officials and large sums of money.

\subsection{Pilot Review Tanzania, UNCAC (2008)}

Tanzania was one of the first countries to sign and ratify the United Nations Convention Against Corruption. In the wake of UNCAC, a monitoring process has been piloted, with Tanzania acting as pilot review country. Some of the issues addressed above are included in this monitoring process, namely the question of implementation of the "impressive anticorruption laws" (UNCAC 2008: 3) of Tanzania. Other issues reflect the concerns stated in the Global Integrity Reporters Notebook, for instance with regard to the prosecution of grand as well as petty corruption cases as well as with regard to attention to a sharper separation of powers (see UNCAC 2008: 3-4). In the executive summary, the report also underlines the need for stricter implementation and oversight of procurement laws, a finding that will be taken up in the following chapters. The report states:

Capacity in public procurement, both at implementing and oversight level, is a problem that needs to be addressed. Increased compliance with procurement laws will reduce corruption risks in an area which constitute $70 \%$ of public expenditure (UNCAC 2008: 4).

62 See Sebastian Sanga (Tanzania: Reporter's Notebook, Global Integrity Report, Assessment 2007) under http://report.globalintegrity.org/Tanzania/2007/notebook (last accessed 5 March 2010). 
The statement underlines the fact already read in between the lines of the Global Integrity Index, namely the there is palpable discrepancy between tightened institutional framework, designed with international guidance, and the actual practices that are predominant, here in the construction sector.

\subsection{Eastern African Bribe Index Report (20og)}

The mapping of corruption has been fine-tuned in a recent large comparative survey of Eastern Africa (Kenya, Tanzania and Uganda), which takes a more focused look at perceptions of and experiences with bribery. Notably, the term 'corruption' has been narrowed down to 'bribery' to avoid problems of divergent meanings of corruption. The following excerpt of the Eastern African Bribe Index (EABI) gives a clear assessment of types and extent of bribe-paying in Tanzania:

The respondents reported having paid bribes for five reasons as follows;

1. To access or speed up services;

2. To avoid the consequences of failing to comply with a certain regulation or to speed up a process e.g. business licensing;

3. During interaction with law enforcement agencies;

4. For employment related services like recruitment, promotion or transfer;

5. For business purposes like acquisition of tenders.

Even though $55 \%$ of the bribery incidences in Tanzania by respondents were for services, bribes paid for services constitute only $13 \%$ of the total value of bribes paid. $41 \%$ of the total value of bribes paid was for employment related issues. This underpins the premium attached to job seeking. While the survey indicates that only $4 \%$ of the bribery situations and total value of bribes were for business related purposes, this does not accurately reflect the level of integrity in public procurement but rather that the household survey targeted ordinary Tanzanians who may not have regular business interactions with public institutions (Transparency International Kenya et al. 2009: 31-32).

The results from this survey provide a far more nuanced profile of 'corruption' in Tanzania. There does not seem to be pervasive patronage or clientelism, except, arguably, with regard to job seeking. With over half of the respondents encountering bribery demands with services, petty corruption is very frequent ('petty' as the value of the corrupt transaction is relatively low, as Table 5, below, shows). For our purposes, the statement on integrity of public procurement above will be of particular relevance, as the case-studies will be looking into professional associations whose members depend on public procurement in the construction industry. 
Table 5: Analysis of Bribery in Tanzania by Purpose

\begin{tabular}{lr}
\hline Number of Transactions (Percent of Total) \\
\hline Services & $55 \%$ \\
Regulatory Compliance & $6 \%$ \\
Law enforcement & $23 \%$ \\
Employment & $12 \%$ \\
Business & $4 \%$ \\
\hline Value (Percent of Total) & \\
\hline Services & $13 \%$ \\
Regulatory Compliance & $13 \%$ \\
Law enforcement & $29 \%$ \\
Employment & $41 \%$ \\
Business & $4 \%$ \\
\hline Average Size of Bribe (Tsh) & \\
\hline Services & 42348 \\
Regulatory Compliance & 40261 \\
Law enforcement & 91721 \\
Employment & 129365 \\
Business & 13167 \\
\hline
\end{tabular}

(Source: Transparency International Kenya et al. 2009: 32, Figure 26)

In regional comparison, the survey demonstrates that Tanzania fares by far the best out of the three countries: "The overall level of corruption as reflected by the proportion of East Africans from whom a bribe was solicited or expected during service interaction stood at $34.6 \%$ for Uganda, 17\% for Tanzania and 45\% in Kenya" (EABI 2009: 10; emphasis added). This puts corruption into a regional perspective, although, as relevant statements by respondents for instance from MKUKUTA or the Afrobarometer show, citizens in Tanzania do not find this to be an acceptable level of corruption.

\subsection{National Governance and Corruption Survey (NGCS) (2009)}

In November 2009, the first baseline survey aimed at gauging good governance and corruption situation in the country was presented (but not yet available to the public). Although, as mentioned under the section on the 'First Annual Report on Corruption' of 2001, that was originally intended to be the first baseline survey of a series of annual reports, the quality of the first report was criticised. The NGCS is designed as the "first 
ever composite baseline survey of governance and corruption in Tanzania" (PCCB 2009:xi), designed as a basis for policy reform. The survey, which is far more systematic and comprehensive in its methodology than the First Annual Report on Corruption in Tanzania of 2001, covers households, public officials and enterprises.

The key findings underscore some of the results of the EABI and other corruption surveys. Corruption is consistently ranked as a serious problem by respondents of all three sectors, with the private sector reporting the obligation to pay bribes more frequently than households and public officials. Interestingly the "leading cause of corruption is attributed to greed. This is followed, for households and public officials by moral indecency and poor law enforcement; and for company executives by the lack of control and accountability of public officials, and moral decay" (PCCB 2009: xiii) ${ }^{63}$ Again this is an unambiguous statement against justifying corruption in terms economic hardship or culturally hybrid values. Like the previous surveys, it also gives some indication about the expectations that Tanzanians generally have of the state and government, namely integrity and accountability. Interestingly, the survey makes an explicit, unambiguous correlation between greed, grand corruption and poverty, as Figure 7, below, shows.

The survey finds that in the majority of cases $(83 \%)$ it is government officials who initiate corruption, as opposed to $11.8 \%$ of citizens. The figures shift in the case of responses from enterprises, with $64.9 \%$ of government officials initiating corruption and $18.2 \%$ of business people (and $16.9 \%$ being tacit understanding or facilitated by brokers) (PCCB 2009: 13).

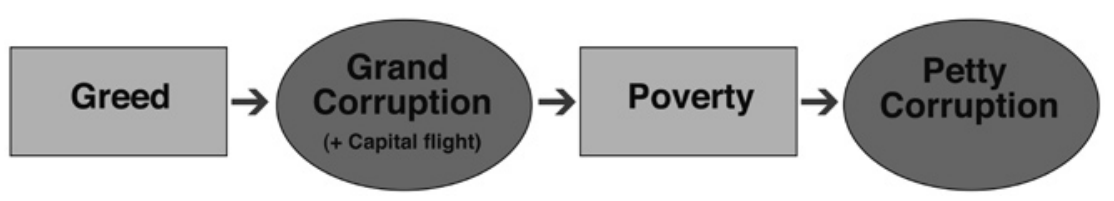

(Source: PCCB 2009: 12)

Figure 7: Causal Chain of Types of Corruption According to the NGCS

63 This response is quite overwhelming, with $96.2 \%$ of households, $96.6 \%$ of public officials, and $95.5 \%$ of company executives attributing the main cause of corruption to greed and selfishness (PCCB 2009: 11-12) (although one could arguably make a difference between greed and selfishness). 


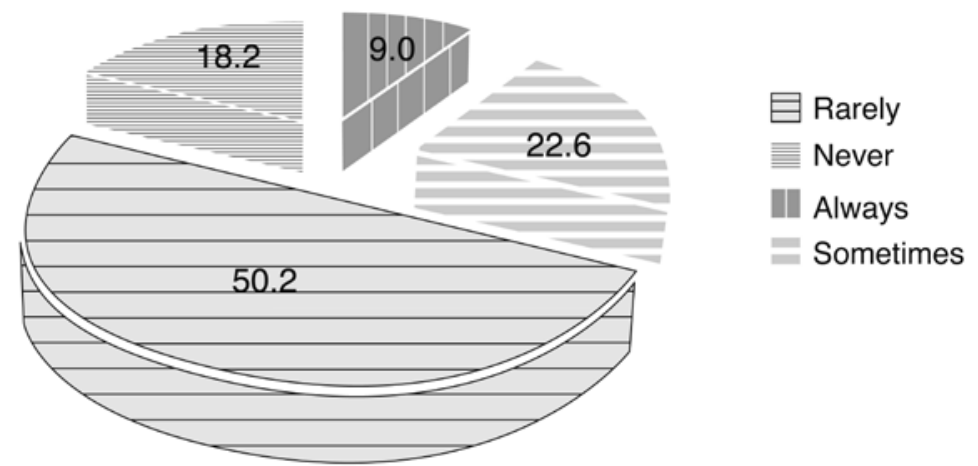

(Source: PCCB 2009: 19)

Figure 8: "Percentage distribution enterprise [sic] reporting frequency of government procurement tenders being awarded in a clear and efficient manner"

A section of particular importance for the case-studies is on "quality and efficiency of public service delivery" (PCCB 2009: 18-21), as it also measures corruption in public procurement. As can be seen from Figure 8 (above) on government procurement tenders, a majority of respondents from enterprises dealing with public procurement reported corruption. In particular, they specified that

public tendering processes are beset with several malpractices, which are done frequently, notably:

- bid rigging (reported as being frequent by 83.3 percent of respondents);

- qualified bidder being disqualified at pre-qualification stage (76.7 percent);

- adjustment of specification in the interest of a favoured company (68.9 percent);

- leakage of client's budget at tender stage (67.5 percent); and

- modification of contract terms during implementation stage, i.e. after award of tender (67.6 percent)

Enterprises further reported that having 'connections' and making of an 'unofficial payment' are important factors to win a government contract, according to 68 percent and 63.7 percent of respondents, respectively, and that, on average, public procurement contracts involve unofficial payments amounting to 10.4 percent of the contract value. Regional comparisons reflect significant differences in the quantum of bribes paid, which is higher than the national average in Mara region (25 percent of contract value), Dar es Salaam (14 percent) and Lindi region (12 percent); while in Tanga, 
Ruvuma, Iringa, Tabora, Rukwa and Kigoma regions the bribe paid is three percent of the contract value or lower" (PCCB 2009: 19-20).

The survey results indicate the pervasiveness as well as the diversity of corrupt practices in construction and public procurement. The height of the corrupt 'cut' out of government contracts leads the report to conclude in its Executive Summary that "[p]ublic procurement and contracting sectors are prone to grand corruption" (PCCB 2009: xvi).

Summing up, the findings of the report are very comprehensive and methodologically sound. Similar to the first Annual Report on Corruption of 2001, however, the conclusions of the report are rather thin, in spite of much data on which to substantiate these reforms. The conclusions stress mainly that diagnostic capacity need to be strengthened. Perhaps, however, the stated purpose of the report being to act as a baseline does not lend itself to politically outspoken statements and specific policy recommendations.

\section{An Overview over Corruption in Tanzania}

The longitudinal topography of corruption in Tanzania outlines a rather rugged landscape, perhaps not surprisingly given the diversity of survey tools. A rattle-bag of components is produced in these surveys and reports, some of which link up to regularised patterns, others making far more dispersed and marginal statements. On the one hand, corruption is viewed and experienced as a pertinent problem encountered routinely in daily interactions with public officials and public services. However, there are quite an amount of dispersed statements documenting a (in places significant) decrease of experiences and perceptions of corruption, for instance in the widely disseminated Afrobarometer survey (2006) or in the regional comparison made by the EABI. Clearly carved out is that the extent of bribery and corruption varies significantly between services, with decreases witnessed in all areas. The represented improvement over time underlines the positive trend of the aggregate governance and corruption indices. Hence, it is perhaps surprising that these positive statements are not emphasised far more, illuminating the improvements and achievements in the state of governance and corruption in Tanzania. ${ }^{64}$

64 This is not intended as a flippant remark. Evidently, looking just at the break-down of frequency and value of corrupt transactions provided by the EABI (see Table 5 'Analysis of Bribery in Tanzania', above), shows that corruption is still extensive. 
For on the other hand, and far more audibly, the surveys nearly all articulate a cheerless image of Tanzania, evoking old and emerging practices of corruption threatening the state of the nation. Particularly problematic areas emphasised in the surveys and reports are the police, public procurement and local governmental authorities. In addition, in more recent reports the institutionalisation of grand corruption is depicted as a serious and potentially uncontrollable problem. Although the statements in more descriptive reports are most colourful, such as for instance in Global Integrity's Reporter's Notebook, equally trenchant is the latest National Survey on Governance and Corruption (NSGC 2009), which draws a direct correlation between grand corruption, poverty, and petty corruption (see Figure 7 'Causal Chain of Corruption', above). Contrary to the topography of corruption in Tanzania as viewed from a bird's eye view, this perspective infers that grand corruption is a regularised feature of Tanzania's economic and political order.

A further statement made across reports is that there is a more or less glaring discrepancy between the achievements in terms of institutional reform and institutionalised practices. The reasons are only dwelled on in the more qualitative reports, which represent the mind-sets of public officials as an obstructing factor, as well as problems arising out of the implementation, coherence and communication of such reforms. Some diagnose a systemic problem, in which reforms do not 'bite' as intended, but merely mould themselves around entrenched mechanisms of corrupt practices. This is one reason why the importance of public sensitisation and awareness raising is emphasised in many different settings. However, the question remains how the topography of corruption can be modified and reorganised to make more space for non-corrupt, rule-based practices.

This brings us squarely to the question of social agency. The surveys themselves say very little on such agency, reproducing with more or less analysis the findings of the questionnaires, although there may be speculative statements on the extent of (dis)empowerment of citizens in or between the lines. ${ }^{65}$ The reports are more explicit in this regard, most notably the Warioba Report that condemns the blatant abuse of the rule

65 For instance, the Afrobarometer (2006) comments a significant difference between those who reported to have been asked for bribes in medical clinics (26\%), and those who say they actually paid a bribe $(15 \%)$ in the following words: "The difference suggests that Tanzanians are also feeling increasingly empowered to resist such demands" (Afrobarometer 2006: 6). 
of law infringing on citizens rights. But also, albeit couched in more developmental speak, MKUKUTA, which addresses the negative correlation between corruption and poverty, and corruption and democratisation. Due to the nature of most of the reports and surveys, however, they generally provide either scientifically grounded accounts of citizens' perceptions of their (social, economic, political) room to manoeuvre, for instance as measured in relation to the frequency and value of bribes for service delivery or obstructions by public authorities. Or then they seek to provide interventionist policy analyses, in the sense of prescriptive reforms and recommendations, for instance with regard to civic participation. ${ }^{66}$

What the reports and surveys inherently do not capture (and, fairly, do not seek to capture), are the political and economic spaces that citizens do create; the spaces that are not only created in spite of high levels of corruption, but spaces that are created because of corruption. This is a theoretical and empirical lacuna which I hope to illuminate in more detail. To avoid a fundamental misunderstanding: corruption in this sense does not mean an instrumentalisation of corrupt practices, as for instance concepts of neo-patrimonialism or intrumentalisation of disorder signify. What I intend to explore in the the two following case-studies is the ways in which the discourse(s) of corruption are appropriated and filled with particular meanings of social agents, and thus serve to advance their own agendas of political and economic and social demands and interests. More specifically, based on the thoughts sketched out in Chapter 2 (above), I seek to understand more fully the ways in which collective interests are articulated, using corruption and the fight against corruption as an empty signifier to carry their own agenda into a wider public space and connect up to further discourses. Potentially, as is my hypothesis, thus creating hegemonic representations of a specifically democratic, emancipatory nature.

One set of questions arising is to which extent this process actually collapses or, rather, modifies their particular identities, requiring an empirical response. Another set of questions relates to whether and how the hegemonic representations of corruption achieve a universalising effect that

${ }^{66}$ Note for instance Recommendation IV (out of five) of the NSGC: "The government needs to strengthen collaboration with all stakeholders involved in fighting corruption. The main organs in the civil society and private sector that are active in combating corruption include the media, faith-based organizations, NGOs and professional associations. Effective strategies of engaging these organs should be worked out. If real change is to occur, anti-corruption efforts must go beyond state interventions: other non-state actors must be actively mobilised" (NSGC 2009: 44; emphasis in original). 
realise the possibility of democratic society. In the previous two chapters, I have already outlined the concrete historical conditions and contours under which the hegemonic representations of corruption as articulated by the scholarly and development community has emerged. What I seek to do is to identify particular representations of corruption by social agents and explore their universalising potential—with the risk that they may remain pure particularities, and be absorbed by the dominant system. Translated into empirical terms, how do social groups employ 'corruption' as an empty signifier? What claims and struggles are articulated in the discourse of corruption? And what hegemonising processes are initiated to achieve a universalising effect? These are the questions I shall turn to in the following two chapters (Chapters 3 and 4), exploring realities of professional associations in the construction sector of Tanzania. 